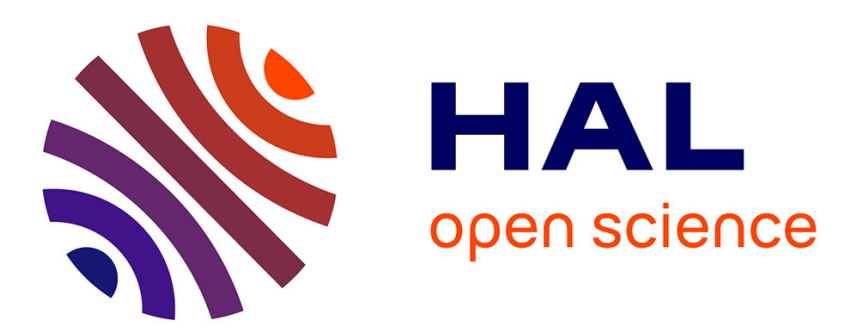

\title{
Digital modelling and stereolithographic production of a Homo Erectus skull
}

François Pérès, Farid Taha, Marie-Antoinette De Lumley, Emmanuel Cabanis

\section{To cite this version:}

François Pérès, Farid Taha, Marie-Antoinette De Lumley, Emmanuel Cabanis. Digital modelling and stereolithographic production of a Homo Erectus skull. Rapid Prototyping Journal, 2004, vol. 10 ( ${ }^{\circ}$ 4), pp. 247-254. 10.1108/13552540410551379 . hal-01295739

\section{HAL Id: hal-01295739 \\ https://hal.science/hal-01295739}

Submitted on 31 Mar 2016

HAL is a multi-disciplinary open access archive for the deposit and dissemination of scientific research documents, whether they are published or not. The documents may come from teaching and research institutions in France or abroad, or from public or private research centers.
L'archive ouverte pluridisciplinaire HAL, est destinée au dépôt et à la diffusion de documents scientifiques de niveau recherche, publiés ou non, émanant des établissements d'enseignement et de recherche français ou étrangers, des laboratoires publics ou privés. 


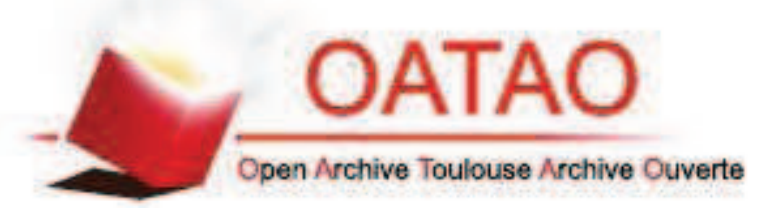

\section{Open Archive TOULOUSE Archive Ouverte (OATAO)}

OATAO is an open access repository that collects the work of Toulouse researchers and makes it freely available over the web where possible.

This is an author-deposited version published in : http://oatao.univ-toulouse.fr/ Eprints ID : 10356

To link to this article : DOI : 10.1108/13552540410551379

URL : $\underline{\text { http://dx.doi.org/10.1108/13552540410551379 }}$

To cite this version : Pérès, François and Taha, Farid and Lumley, MarieAntoinette de and Cabanis, Emmanuel Digital modelling and stereolithographic production of a Homo Erectus skull. (2004) Rapid Prototyping Journal, vol.10 ( $\left.\mathrm{n}^{\circ} 4\right)$. pp.247-254. ISSN 1355-2546

Any correspondance concerning this service should be sent to the repository administrator: staff-oatao@,listes-diff.inp-toulouse.fr 


\section{Digital modelling and stereolithographic production of a Homo Erectus skull}

\author{
François Pérès \\ Farid Taha \\ Marie-Antoinette de Lumley and \\ Emmanuel Cabanis
}

\section{The authors}

François Pérès is based at Ecole Nationale d'Ingénieurs de Tarbes, Tarbes, France.

Farid Taha is based at Service de Chirurgie maxillo-faciale, CHU d'Amiens, Amiens and at Université de Technologie de Compiègne, Compiègne, France.

Marie-Antoinette de Lumley is based at Laboratoire de Préhistoire, Institut de Paléontologie Humaine, Paris, France. Emmanuel Cabanis is a Professor based at the Service de Neuroimagerie Paris Cedex, France.

\section{Keywords}

Head (anatomy), Rapid prototypes, Evolution, Modelling

\section{Abstract}

The National Museum of Natural History has been carrying out, over the last several years, a study of hominid fossil skulls, which have been discovered in different regions of the world. The aim of the palaeo-anthropological study of these skulls is to reconstruct the genealogic tree of the evolution of man and to understand better, the diversity of the homo Erectus species on the different continents. Currently, digital techniques and those of rapid prototyping offer a solution to these problems by allowing the virtual or physical reconstitution of the skulls for scientific study. This paper presents this new perspective for the world of palaeontology.

\section{Introduction}

The observation of fossils, and particularly of skulls, is at present the best method available to gain more knowledge about the mechanisms which have led to the evolution of modern man. The study of fossils is, however, held up by two major obstacles. The first concerns the obvious fragility of the objects found which prevents over handling of them. The second is connected to the unique character of the pieces, prohibiting physical reconstitution by adjusting and assembling the parts of different skulls in order to make a whole. Such operations would lead obviously to the destruction of the original skulls which is not an acceptable solution. The new digital technologies and rapid prototyping allow, nowadays, the study of these fossils in detail without fear of damaging the originals. The objective of this paper is to describe the different links of the study which was carried out. The paper is divided into four parts.

The first part deals with the description of the aim of this research based on the reconstitution of the skull fossils to improve the knowledge of their anatomy, to compare them, and to place them in their taxonomic framework. The following two chapters describe the initial steps of the research work. Actually the second part is concerned with the acquisition of the digital data by the use of a medical scanner for the numerical reconstitution of the fragments of skulls. The third part speaks of the virtual process of bringing together and adjustment of parts of complimentary, skulls. The fourth and final part deals with the stereolithographic fabrication of the skulls. A justification is made about the choice of this type of technology and the protocol of use is described.

\section{Context and goals}

The study of different human skull fossils is complex but presents, however, a major interest for the comprehension of the evolution of the Homo genus and the interpretation of the morphologic diversity of the fossils of the human species. The difficulty of the complete study is due to three major reasons.

(1) Skull fossils are rare and very fragile. At each handling, the risk of losing an important piece 
(2) All of the original fossils, and even more particularly the skulls, are preserved in the safety vaults of different countries such as Kenya, Ethiopia, China, Georgia, France, ...

(3) Access to internal structures of the skull, such as the internal ear, the sinus cavities of the face, the thickness and structure of different bony tissues, the imprints of the internal vascular system of the cranial cavity, ... is impossible with classic methods of investigation (Widianto and Grimaud-Herve 2000). Furthermore, it is essential to be able to compare different fossils with each other during a study (Grimaud-Herve, 1997). The fact that the fossils are located in different parts of the world makes it necessary to work with reconstitutions or mouldings available in the labs (stereolithography or polyamide powder sintering).

In this framework, the study covered skulls discovered at Dmanissi (Georgia) in 1999 (Gabounia et al., 2000). These skulls, dating from 1.7 million years, are very important in order to understand the history of our genus since these are the oldest known Europeans. They present a double interest for they not only invalidate the hypothesis of the late population of Europe (Detroit, 2000), but they also show that Homo Erectus left the cradle of Africa very early (Sémah et al., 2000). In fact, the first known Homo Erectus, dating 1.8 million years, comes from Africa. None of these skulls are complete, but they are, however, very "beautiful" from the palaeontological point of view because they still present an important number of structures. Plate 1 shows one of the skulls of Dmanissi (D2282).

Plate 1 The Dmanissi skull No. D2282

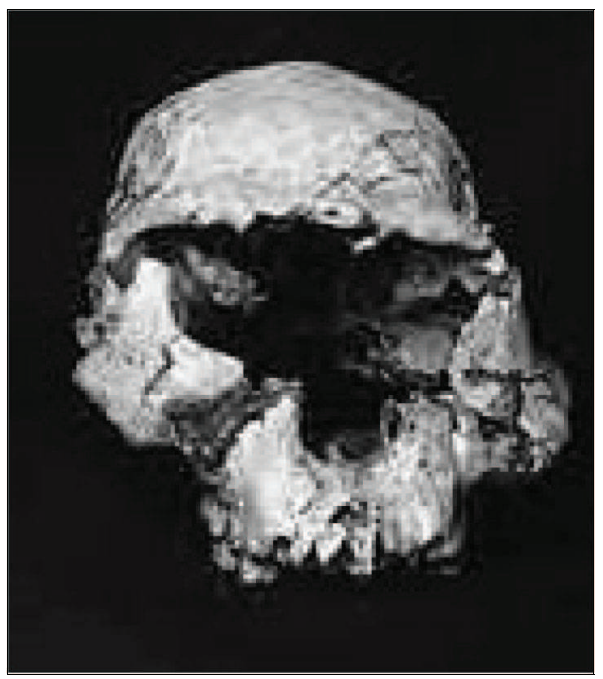

The second object of the study (D2280) will be presented later on in this paper.

The aim of this work was to compare the virtual images of four faces of human fossils (KNM-ER 3733; KNM-ER 1470; KNM-ER and KNM-WT 15 000) with the Dmanissi skull No. D2280. It has not yet been possible to do the study on the second skull (D2282), because it has significant deformations that require the total virtual reconstruction, which is time-consuming. The results obtained allow a more precise description of the D2280 skull and at the same time, enable to place it more exactly in its taxonomic framework. The different steps of this study not only lead to the physical duplication of the skull in resin but also to fabricate skulls resulting from the virtual assembly of several fragments from real skulls.

The reconstitution of these skull fossils by rapid prototyping means that it is possible to have the permanent presence, in the laboratory, of the moulding which best corresponds to the current theories and, thus, be able to compare this reconstitution with other skull fossils. This work allows a new approach to fossils which will be rich in discoveries because it opens access to structures which had been until now either practically or totally inaccessible.

Some works using stereolithography techniques have already been carried out in the field of paleontology. It can be referred in particular to D'Urso et al. (2000) or Zhang et al. (2000).

The aim of these studies was to show the way to proceed to the reconstitution of biological structures through three-dimensional computed tomography and stereolithography. The conclusion of these works show that stereolithographic biomodelling allows both internal and external features of fragile specimens to be be safely replicated without risk. A similar work related to design methods for medical rapid prototyping (Hieu et al., 2003) used the same techniques to correct some skull defects and proceed to the elaboration of personalized cranioplasty implants.

These advances in the domain of human palaeontology are made possible only by the common contribution of multidisciplinary means and skills. It is not surprising, then, to find that the institutions involved in this study include laboratories of paleontology (Institut de Paléontologie Humaine du Muséum d'Histoire Naturelle de Paris) as well as two Hospitals (the CHU d'Amiens and the CH National d'Ophtalmologie de Paris) and a centre of technology transfer specialising in rapid prototyping (Create from the Industrial Engineering laboratory of the Ecole Centrale of Paris). 


\section{Acquisition and treatment of data}

\section{The acquisition of data}

Even though it possesses a certain number of qualities (digitalization without contact, precision, fidelity of reproduction, etc.), the 3D surface digitalization as it is presented today in certain industrial frameworks can no longer be used in order to obtain geometric data of skulls. Indeed, there are two reasons which prohibit its use:

- The digitalization of skull fossils discovered in the Dmanissi site has to be as a-traumatic as possible, reducing to a strict minimum the direct manipulation of these skulls which are more than 1.5 million years old.

- Certain geometric information recorded on the internal aspect of the skulls (and thus nonaccessible to conventional industrial digitalization techniques) may turn out to be of extreme importance for the palaeontologist because they preserve the form of the brain.

They constitute what is, in effect, the negative or the impression of the cerebral form left by the imprints of the dura mater (the term dura mater refers to the leathery outermost of three membranes, or meninges, that encapsulate the brain and the spinal cord).

The medical scanner or X-ray scanner consequently turns out to be the ideal solution for a tri-dimensional virtual, then physical, reconstruction of the skull. The total anatomy of the region explored, i.e. the superficial as well as deep structures, are accessible, the bony architecture being preserved due to the accuracy of the acquisition technique and the facility of access. Moreover, certain data such as the densometric or more precisely the tomodensitometric profile of fossilized bones may turn out to be very useful to the palaeontologist in order to understand their interaction with the environment in which they were fossilized. It will thus make easier the understanding of the phenomenon of fossilization following burial in a sandy, calcareous, or other medium.

\section{Method of acquisition of data}

The technique and the parameters of acquisition of data for this type of anatomic bony structures are already well-codified in current practice. A few things that may change are the doses of $\mathrm{X}$ rays in kilovolts and milliampere second necessary to do tomodensitometric sections in the case of fossilied bones. The dose of rays need to be increased in relation to the amount of sediment still attached to the skull. Tomodensitometric examination was used for all the skulls by Service de Radiologie du Centre Hospitalier de neuro-Ophtalmologie du $\mathrm{XV}-\mathrm{XX}$ according to a standardized procedure for acquisition of data from bone tissue on a General Electric HiSpeed RP scanner allowing a helical or spiral acquisition. The technical parameters and scanner settings were the following.

- Matrix of acquisition $(512 \times 512$ pixels);

- Width of section (1 mm);

- Size of voxels $\left(0.49 \times 0.49 \times 1 \mathrm{~mm}^{2}\right)$

- Field explored (approximately $2,500 \mathrm{~mm}^{2}$ ).

The position of the skulls on the scanning table in relation to the statif or stand, is often constrained by technical considerations due to their fragility and sometimes due to the sediments still attached to the fossils which have been impossible to remove.

The scan data are recorded according to the DICOM Norm (a standard of data formatting and of communication used in medical imagery). The conversion and processing of data are almost entirely automated. The only parameters that may change are those of the image segmentation (thresholding). It may, for instance, be adjusted for each skull according to its densometric profile.

An example of the results of such a procedure is shown in Figure 1.

\section{Digital reconstitution of an incomplete skull}

The initial objective is to find a face which could be adapted to one of the Dmanissi skulls (the D-2280) in order to complete it, while at the same time respecting a certain number of reconciliation criteria.

- Anthropomorphic considerations: bones of individuals of the same sex and age class.

- Geographic considerations: the fossils must come from regions between which migrations of population is plausible;

- Age considerations: the individual parts must belong to the same era.

A pre-selection, put together by a team from the Institute of Human Palaeontology of the Museum of Natural History of Paris (By professor Henry de Lumley) allowed to have only skulls which responded to these criteria for this study. In order to test the adaptation of the skulls, digital models were created.

The protocol for this study is presented in Figure 2.

This protocol is composed of five stages:

- Step 1 - choice of a complementary skull. Consists of choosing the skull of which it wanted to analyse the feasibility of approximation with the skull which is the object of the study (in this case, the D2280). In the framework of this study, approximation 


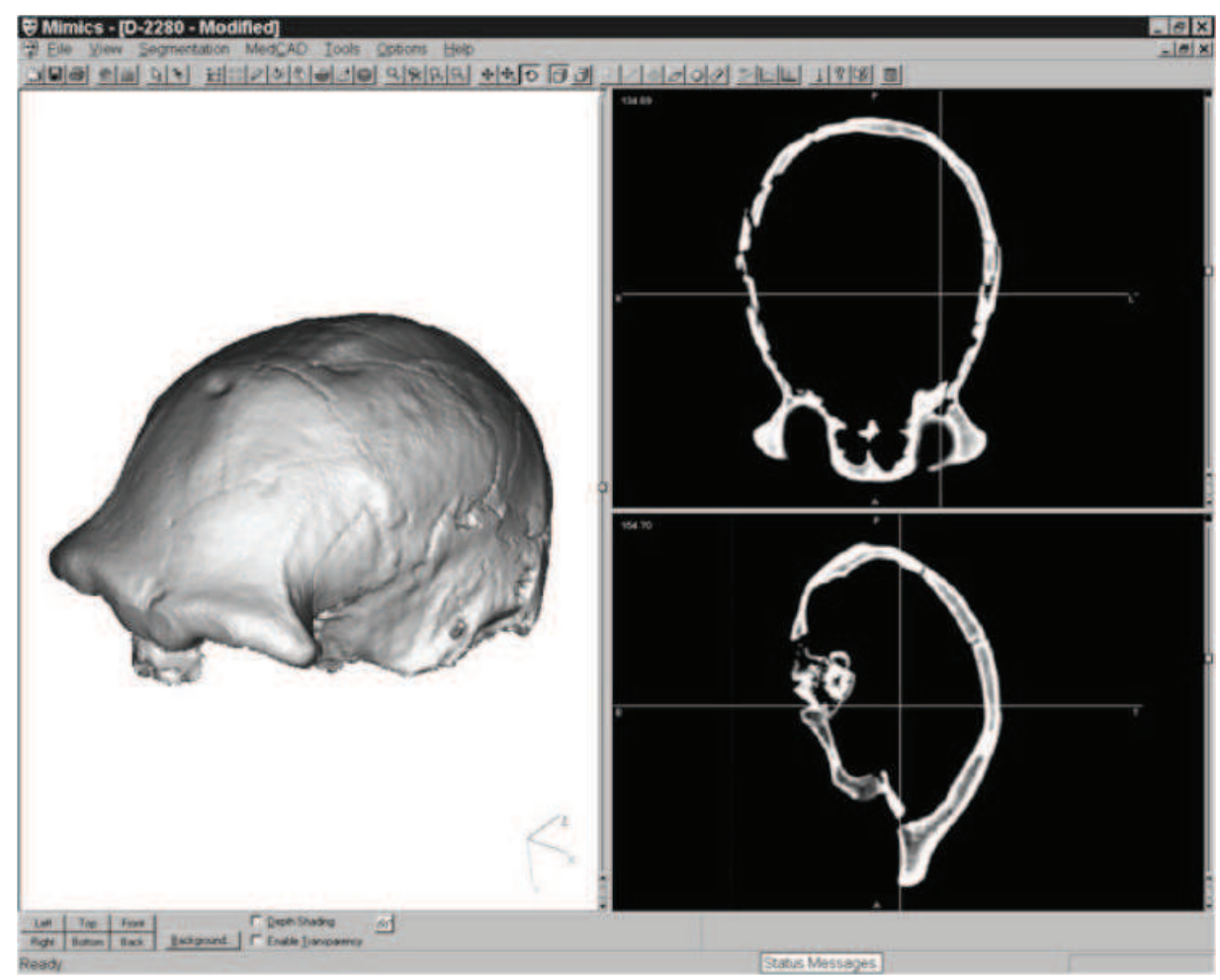

analyses were carried out between the D2280 and four other skulls (KNM-ER 3733; KNM-ER 1470; KNM-ER 1813 and KNM-WT 15,000).

- $\quad$ Step 2 - acquisition of data. As mentioned earlier, the skulls are scanned with a medical scanner and the data are entered in DICOM format (standard medical imagery).

- $\quad$ Step 3 - three-dimensional reconstruction. From the information obtained by scanner, a threedimensional reconstruction is created using Mimics ${ }^{\circ}$ [1] Software. These 3D models are then transferred in an STL format in order to be controlled (normal directions) with Magics ${ }^{\circledR}$ Software.

- $\quad$ Step 4 - visual adjustment. The files representing the skulls digitalized in three dimensions are exported to tools which allow the conversion of this $3 \mathrm{D}$ data into a hyperrealised form. The software used for this step is Softimage $\left|\mathrm{XSI}^{\odot}\right|[2]$.

- $\quad$ Step 5 - automatic approximation for reconstitution of a skull. By digitally bringing together the different fragments of skulls, a new skull is created. This bringing together of parts of skulls may be manual or automated according to the recognition of similarities. This automatic approximation is produced using Amira ${ }^{\circledR}[3]$ Software.

\section{Stereolithographic fabrication of skulls}

Choice of the type of technology

The digital files produced were then used for fabrication purposes following a rapid prototyping process. These, still emerging technologies (the most recent being only about 14 years old) are based on the aggregation of material, layer by layer, by a physical or chemical transformation. The materials used are in the form of liquids (resins), or solids (either one-dimensional powders, two-dimensional - sheets, or three-dimensional - plates). The process of transformation which consists of two phases - that of obtaining a section, and that of aggregation to the preceding sections - can be done without changing the state of the material (cutting, and stacking) or with a change of state (fusion, polymerisation, pasting, and soldering).

The choice of this type of technology is obvious when considering the complexity of the forms that palaelontologists work with; it would be nearly impossible to elaborate them by conventional means (that is to say, by procedures belonging to the group of subtractive methods or by removing material from an original block) (Pérès and Martin, 1999).

It can be noted that other factors exist in favor of prototyping technologies for the anthropologic study. 
Figure 2 Protocol for digital processing of a skull

Dmanissi 2280
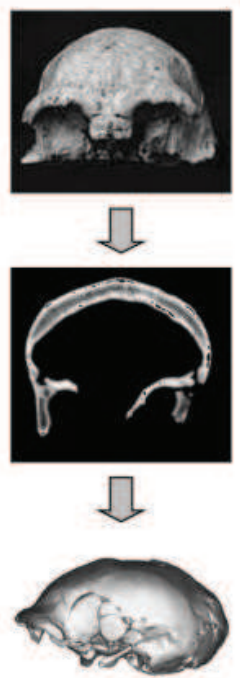

\)

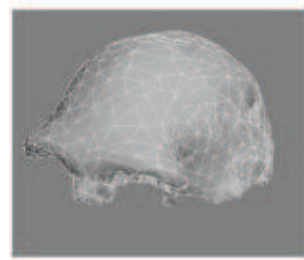

\section{KNM WT 15000}

Step 1 Choice of a skull complementary to theDmanissi D-2280 skull
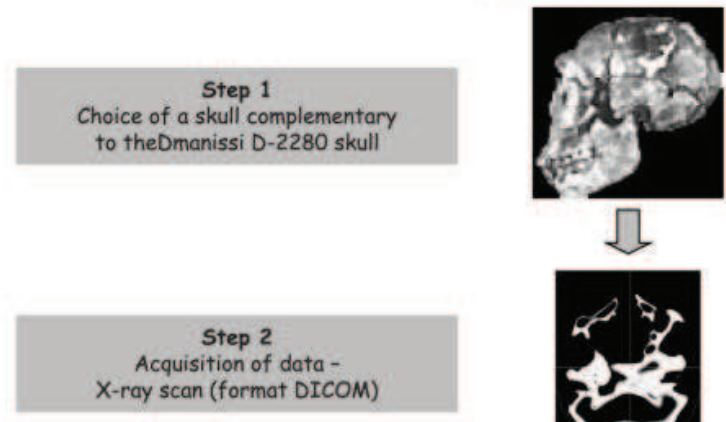

』
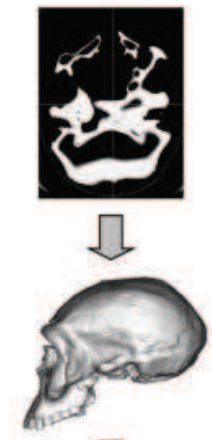

几

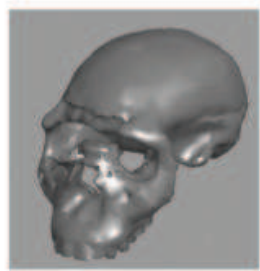

\section{rocessing of data and}

Step 3

3D Reconstruction

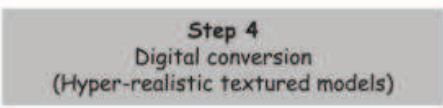

(Hyper-realistic textured models)
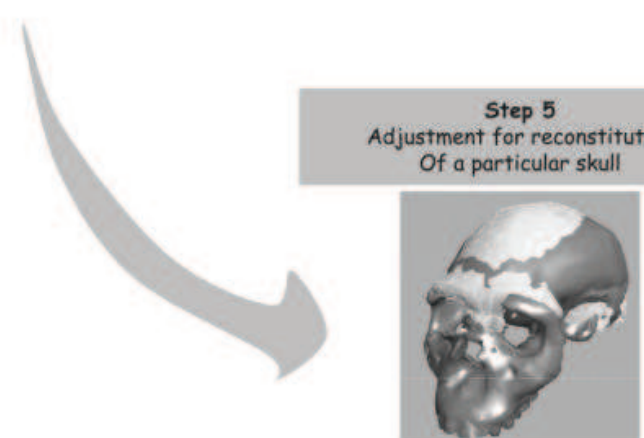

\section{tment for reconstitution} Of a particular skull

- The precision of the technique. It is possible to work with a relatively fine level of detail - in the range of a tenth of a millimetre (with the eventual possibility of finishing it by hand by polishing or sanding).

- The direct link which exists between the digital modelling and the physical realization. There is no need of additional tooling in order to create the object once the digital file is available in the appropriate format.

- The rapidity of performance (even though this parameter is not fundamental in this case). It depends on the volume to be fabricated, the number of layers needed to be made, time between each layer, length of time needed for preparation and finishing.

For a more detailed description of the rapid prototyping technologies, the reader can refer to the work of Alain Bernard and Georges Taillandier (Bernard and Taillandier, 1998) which covers a complete panorama of processes, material and domains of possible application linked to the use of this technology (Bernard, 2000).

At the time of earlier studies, certain skulls were created using a procedure of powder sintering. The results were globally correct but did not produce an excellent quality of finish. For these 
reasons, the Paris Museum of Natural History in the framework of a three-way partnership with the Centre Hospitalier Universitaire (CHU) of Amiens and the Ecole Centrale Paris solicited the help of CREATE[4] in order to create these skulls by means of a process of stereolithography. This procedure, already well known among industrials but until now used very little in the domain of human sciences (medicine, palaeontology, sociology, ...) (Taha and Devauchelle, 1997) is based on the polymerization of a photosensitive resin by a laser which uses light energy. In relation to the technology of powder sintering, this procedure offers particular advantages and disadvantages (linked to the nature of the materials used, their resistance, the presence or absence of supports, the state of the surface which is of greater or lesser quality, ...).

In the framework of the reproduction of fossil skulls, the point against the use of the powder sintering procedure resides principally in that the resulting skull appearance do not meet the expectations of the palaeontologists. On the other hand, stereolithography offers much more satisfying results (Taha et al., 1996). The nature of the material used - resin - allows an effect, if not very close to the texture of bone, at least with a true aspect of the original cranial cavity. In addition, the raw final product of stereolithography can be reworked (by abrasive paper, sand, and eventually paint or varnish) and the finish obtained may erase any imperfections (layers, and surface small defects).

\section{Protocol of skull realization}

The procedure of fabrication of Homo Erectus skulls is not different from other industrial applications. The protocol requires the implementation of a certain number of classic steps which can be found at the level of more conventional parts made by stereolithography.

These steps are described in Figure 3.
Step 1 (few hours). From the digital file of the skull in STL format, digital positioning of the object in the machine vat and calculation of the supports needed for the fabrication of the skulls. The hollow spaces in the cranial cavity allow access to the internal parts of the skull (an important parameter in order to eliminate the supports). The skull was made in a direction corresponding to the vertical position of a human being.

The calculation tool used is the Maestro software.

Step 2 (few minutes). Preparation of the machine - pre-heating of the laser (concurrent with step 1) then transfer of calculations onto the computer driving the stereolithography machine, verification of the level of resin and starting of fabrication

Step 3 (apporoximately $30 \mathrm{~h}$ ). Fabrication of the skull - scale 1; number of layers - approximately 2,000 ; volume of resin necessary $-230 \mathrm{~cm}^{3}$; machine - SLA 250; helium-cadmium laser; power $-\approx 30 \mathrm{~mW}$.

Step $4(1 \mathrm{~h})$. Because the skull is made of a photo-sensitive resin (acrylate) the need for post-treatments is linked to the possibility of deformations when the object is exposed to daylight. In order to avoid this problem, the object is baked in an ultraviolet oven.

Step 5 ( $2 \mathrm{~h}$ ). Cleaning with a solvent and manual elimination of the support generated at the base of the first section and under the parts not naturally supported by the preceding section.

Step 6 (20 min). Finish - polishing of the skull with a fine abrasive paper in order to erase any trace of the supports and to eliminate the stratified effect.

These six steps last for about $48 \mathrm{~h}$ but it is important to note that the time of supervised operation is not more than $3 \mathrm{~h}$. The steps of calculation and actual realisation, which take the longest time, do not necessitate human supervision.

Figure 3 Protocol of stereolithographic fabrication of skulls

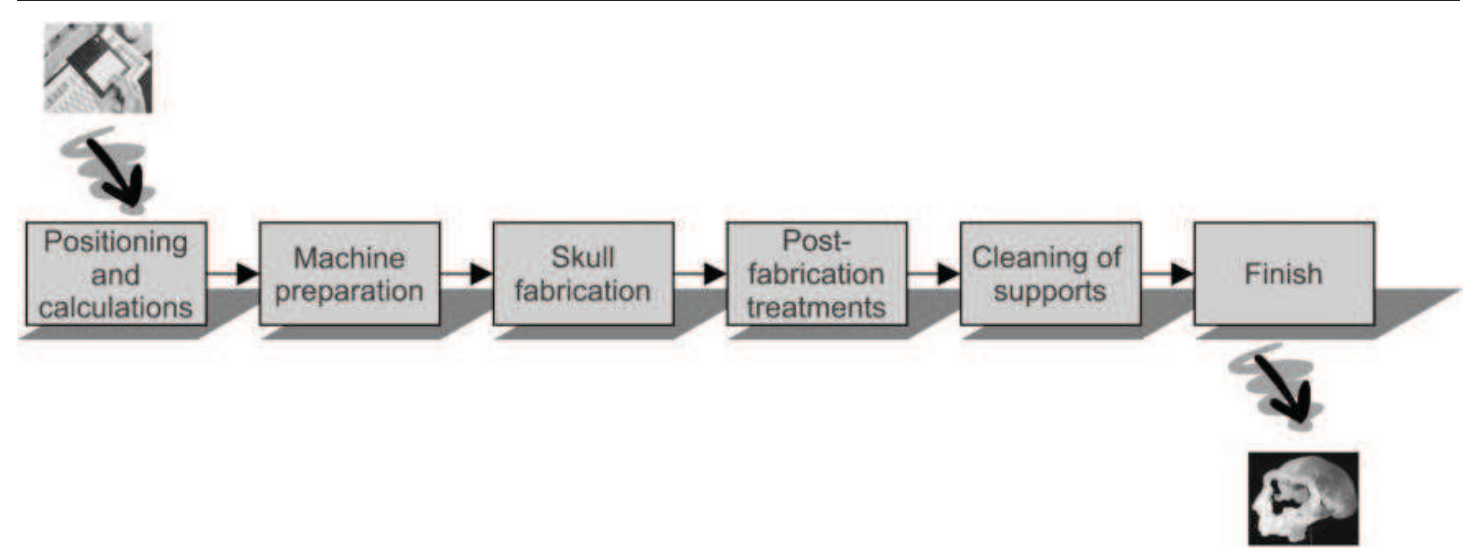




\section{Skull production}

The first phase of production has dealt with two original "Dmanissi" skulls. Plates 2 and 3 present some views of these two skulls.

The second phase of production involved the elaboration of a human skull which has never existed, which resulted from bringing together the Dmanissi D2280 and KNM ST 15000 skulls. The results are shown in Plate 4.

\section{Conclusion}

It is clear that the scientific interest of this paper does not lie in the technology used, in that case digital design and stereolithography. Rapid prototyping is only a tool at the service of research, being done by the Museum of Natural History.

The originality of this work lies in bringing together an advanced technology, which until now has been used primarily by industrial manufacturers, and the scientific sphere of palaeontology - which has been using well-tested techniques, but much more rudimentary, based on moulding. These techniques produce good results but may not in any case be used without physical manipulation of the original object which serves as the model. Furthermore, practically no extrapolation by association of several skulls is possible since, obviously, the fragments found are not strictly complementary. This, naturally, poses a constraint on the analysis by the scientists of the individual skulls.

Only virtual cross-checking from separately observed characteristics on each skull can allow the apprehension of the principles of human evolution. Digital technology allows us to overcome this constraint. There is an unlimited possibility of cuts and assemblies. On the basis of the hypotheses validated by the observation of glaringly obvious complementarities between certain digital zones which have been brought together, it is then possible to recreate a single skull. This modelled skull can then be fabricated by rapid prototyping and can be observed first hand by scientists, which opens new perspectives in the human sciences.
Plate 2 Dmanissi skull D2282
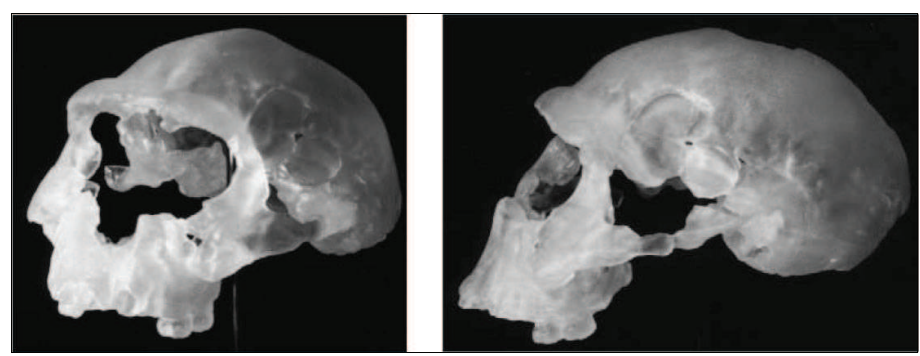

Plate 3 Dmanissi skull No. 2280
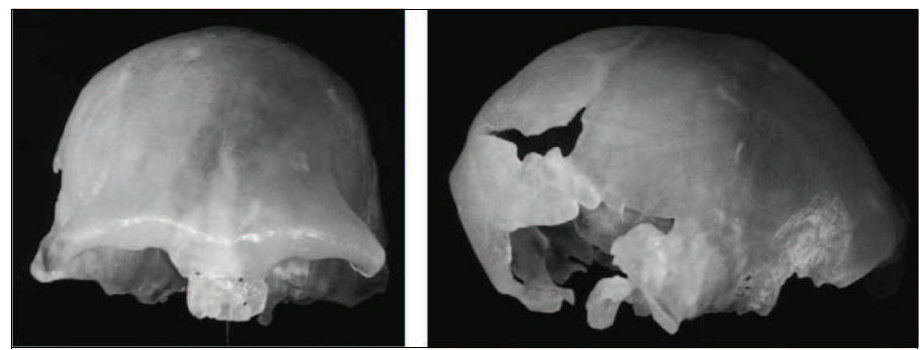

Plate 4 Skull of a man who has never existed
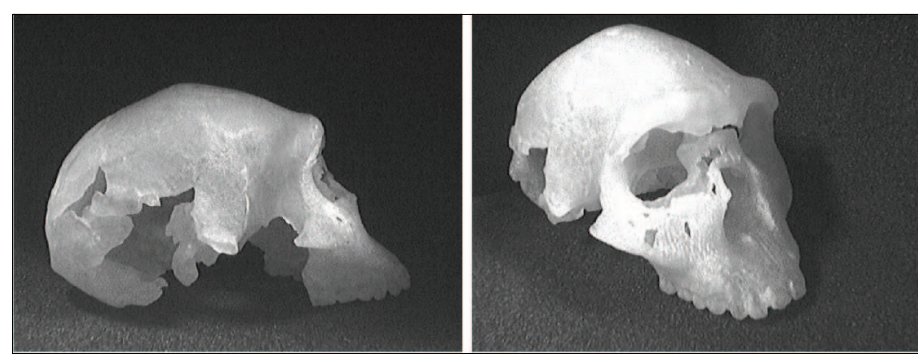

\section{Notes}

1 Developed by Materialise N.V. Louvain (Belgium).

2 Developed by AVID.

3 Developed by TGS, Europe.

4 CREATE: Centre de prototypage Rapide Européen $\mathrm{d}^{\prime}$ Assistance de Transfert et d'Expérimentation of the Ecole Centrale Paris.

\section{References}

Bernard, A. and Taillandier, G. (1998), Le Prototypage Rapide, Editions Hermès, Paris.

Detroit, F. (2000), "The period of transition between Homo Erectus and Homo sapiens in East and Southeast Asia: new perspectives by the way of geometric morphometrics", Acta Anthropologica Sinica, Vol. 19, pp. $75-81$.

D'Urso, P.S., Thompson, R.G. and Earwaker, W.J. (2000), "Stereolithographic (SL) biomodelling in palaeontology: a technical note", Rapid Prototyping Journal, Vol. 6 No. 3 , pp. 212-6.

Gabounia, L., Vekua, A., Lordkipanidze, D., Swisher, I., Carl, K.C., Ferring, R., Justus, A., Nioradze, M., Tvalcrelidze, M., Anton, S., Bosinski, G., Joris, O., De Lumley, M.-A., Majsuradze, G. and Mouskhelishvili, A. (2000), "Earliest pleistocene hominid cranial remains from Dmanisi, Republic of Georgia: taxonomy, geological setting, and age", Science, Vol. 288 No. 5468, pp. 1019-25.

Grimaud-Herve, D. (1997), L'évolution de l'encéphale chez I'Homo Erectus et I'Homo sapiens. Les cahiers de Paléoanthropologie, CNRS Eds, p. 420.

Hieu, L.C., Bohez, E., Vander Sloten, J., Phien, H.N., Vatcharaporn, E., Binh, P.H., An, P.V. and Oris, P. 
(2003), “Design for medical rapid prototyping of cranioplasty implants", Rapid Prototyping Journal, Vol. 9 No. 3, pp. 175-86.

Pérès, F. and Martin, C. (1999), "Design methods applied to the selection of a rapid prototyping resource", Emerging Technology and Factory Automation, ETFA 99, IEEE Proceedings, Barcelone, Espagne, October 1999, Vol. 2, pp. 417-24.

Sémah, F., Saleki, H., Falgueres, C., Féraud, G. and Djubiantono, T. (2000), "Did early man reach Java during the late Pliocene", Journal of Archaeological Science, Vol. 27, pp. 763-9.

Taha, F. and Devauchelle, B. (1997), "Rapid prototyping technologies: a unique approach to the diagnosis and planning of medical procedures", Three Surgical Cases Using Rapid Prototyping Technologies: Contribution to the European Action on Rapid
Prototyping Medical Database Project

Dr K.T Mc Aloon, SME Publishing, Michigan/Dearborn, pp. 141-62.

Taha, F., Devauchelle, B., Segrestin, L. and Testelin, S. (1996), "Prototypage rapide du squelette facial par stéréolithographie, de la 3e à la 4e dimension", Video Film - Prix du Festival du Film médical d'Amiens Pôle Chirurgie (Filmed Septembre 1996).

Widianto, H. and Grimaud-Herve, D. (2000), "Un nouveau crâne humain fossile dans le dôme de Sangiran (Java, Indonésie)", Compte-rendu de l'Académie des Sciences, Vol. 330, pp. 883-8.

Zhang, G., Tsou, Y. and Rosenberger, A.L. (2000), "Reconstruction of the Homunculus skull using a combined scanning and stereolithography process", Rapid Prototyping Journal, Vol. 6 No. 4, pp. 267-75. 